\title{
Characterization of medium-temperature Sasol-Lurgi gasifier coal tar pitch
}

\author{
Gedion Papole ${ }^{1}$, Walter W. Focke ${ }^{2 *}$ and Ncholu Manyala ${ }^{3}$ \\ SARChI Chair in Carbon Technology and Materials, Institute of Applied Materials \\ ${ }^{I}$ Department of Chemistry, ${ }^{2}$ Department of Chemical Engineering, ${ }^{3}$ Department of Physics \\ University of Pretoria, Pretoria, 0002, South Africa
}

\begin{abstract}
Medium-temperature gasifier pitch (MTP) is only partly soluble in acetonitrile, methanol and ethanol. Single-stage pitch extraction with a large quantity of methanol yielded two liquid phases containing 76 wt. $\%$ and 27 wt. \% pitch respectively. The pitch fractions recovered from these two phases featured similar aromaticity indices. However, the pitch from the pitch-rich phase had a higher average molar mass and gave an improved carbon yield at 1000 ${ }^{\circ} \mathrm{C}$. Analysis of the methanol-insoluble pitch fraction showed that methanol extraction at reflux temperatures effectively removed boronic acid model compounds from pitch samples spiked with the same.
\end{abstract}

Keywords: Medium temperature gasifier pitch; solvent extraction; boron; characterization

*Corresponding author: Tel. +27124203728, Fax.+27124202516, E-mail: Walter.Focke@up.ac.za 


\section{Introduction}

Coal tar and petroleum pitches are important raw materials for carbon-based artefacts [1]. These products find application in aluminium and steel production, in construction, in the automotive industry, and in nuclear reactors [2]. Medium-temperature gasifier pitch (MTP) is a by-product of the Sasol-Lurgi coal gasification process. It is graphitisable [3] and as such a potential precursor for nuclear grade materials used in graphite-moderated reactors [2].

Pitches contain a myriad of different compounds [4] and differ with respect to their molecular weight distributions. Solvent extraction tests can provide information about the complex structure of pitches [5-7]. The solubility of pitches in organic solvents such as toluene and quinoline are considered important indicators for industrial applications $[4,5]$. Guillén et al. [5] investigated the extractive ability of 27 organic solvents and concluded that coal tar pitches were most soluble in quinoline and 1-methyl-2-pyrrolidinone. They concluded that no simple relationship exists between the solubility of pitch and the solvent parameters commonly used for correlation purposes [8]. Solvent extraction has also been employed to make superior carbon precursors from coal tar pitch [9]. A key focus of this investigation was to improve the carbon yield of MTP through targeted solvent extraction.

Thermal neutrons are responsible for sustaining the fission processes in nuclear reactors [2]. Carbons for nuclear applications must meet stringent specifications with respect to neutron absorbing impurities such as boron [10]. Owing to boron's high neutron cross section [11], nuclear graphite should contain less than $1 \mathrm{ppm}$ [12]. Boron is a common impurity element present in most carbonaceous materials [13]. It occurs in various forms $[14,15]$ but it is more likely to be associated with the organic part of the carbonaceous material than the mineral matter [14]. MTP would be a good nuclear grade carbon precursor were it not for its high boron content of up to $14 \mathrm{ppm}$. 
Boron atoms are incorporated into the carbon lattice on coking and graphitization. A portion can still be removed by high temperature purification of the graphite in the presence of halogens. However, boron removal by solvent extraction at the pitch stage is a more practical proposition. Ideally the pitch should be insoluble or at most partially soluble while all the boron-containing compounds should concentrate in the extraction solvent. Consequently this study focused on the chemical and physical characterization of MTP including extractions with a range of different solvents. It investigated the feasibility of using methanol as the extractive solvent to improve the carbon yield and to remove boron from MTP laced with selected boron model compounds.

\section{Experimental}

\subsection{Materials}

Sasol supplied the medium-temperature gasifier pitch. The properties of this pitch are presented in Table 1. High purity organic solvents were purchased from Merck. The solvents used include formamide, $n$-hexane, cyclohexane in addition to those indicated in Fig. 1. Boronic acid model compounds, listed in Table 2, were acquired from Sigma Aldrich. They were selected based on their varying aromatic character.

\subsection{Pitch extraction experiments}

\subsubsection{MTP room temperature extractions}

Exploratory MTP solvent extractions were conducted at ambient temperature $\left(25 \pm 5^{\circ} \mathrm{C}\right)$. These batch experiments were performed using $100 \mathrm{~mL}$ solvent aliquots placed in $500 \mathrm{~mL}$ propylene bottles. To these were added tarry pitch quantities of 5, 10, 20, 30, 40 and $50 \mathrm{~g}$. 
Table 1: Properties of MTP and its methanol, benzene and toluene insoluble fractions

\begin{tabular}{|c|c|c|c|c|c|}
\hline \multirow[t]{2}{*}{ Property } & \multirow[t]{2}{*}{ Units } & \multirow{2}{*}{$\begin{array}{c}\text { Parent } \\
\text { pitch } \\
\text { (MTP) }\end{array}$} & \multicolumn{3}{|c|}{ Insoluble fractions* } \\
\hline & & & Methanol & Toluene & Benzene \\
\hline Solvent extraction residue & wt. $\%$ & - & $54.7 \pm 2.3$ & $3.0 \pm 0.01$ & $3.3 \pm 0.01$ \\
\hline Softening point & ${ }^{\circ} \mathrm{C}$ & 38.5 & 59.6 & nd & nd \\
\hline $\begin{array}{l}\text { FTIR absorbance } \\
\text { ratio } A_{3040} / A_{2920}\end{array}$ & - & 0.20 & 0.20 & nd & nd \\
\hline $\begin{array}{l}{ }^{13} \mathrm{C} \text { n.m.r. aromaticity index } \\
\left(\mathrm{f}_{\mathrm{a}}\right)^{* *}\end{array}$ & $\%$ & 78 & 77 & 85 & 85 \\
\hline $\begin{array}{l}\text { Number average molar mass } \\
\left(\mathrm{M}_{\mathrm{n}}\right)\end{array}$ & a.m.u. & 327 & 359 & 432 & 420 \\
\hline $\begin{array}{l}\text { Weight average molar mass } \\
\left(\mathrm{M}_{\mathrm{w}}\right)\end{array}$ & a.m.u. & 403 & 437 & 543 & 553 \\
\hline Polydispersity index $\left(\mathrm{M}_{\mathrm{w}} / \mathrm{M}_{\mathrm{n}}\right)$ & - & 1.23 & 1.22 & 1.26 & 1.32 \\
\hline Carbonyield@1000C & wt. \% & 8.25 & 25.3 & 53.5 & 50.8 \\
\hline \multirow{6}{*}{ Elemental Analysis } & wt. $\%$ & 85.3 & 87.1 & 84.1 & 83.2 \\
\hline & wt. $\%$ & 6.39 & 6.34 & 5.43 & 4.96 \\
\hline & wt. $\%$ & 1.95 & 1.82 & 2.91 & 2.83 \\
\hline & wt. $\%$ & 0.51 & 0.53 & 0.33 & 0.31 \\
\hline & wt. \% & 5.83 & 4.24 & 7.19 & 8.67 \\
\hline & - & 1.12 & 1.15 & 1.3 & 1.4 \\
\hline
\end{tabular}

*Extractions based on $2 \mathrm{~g}$ pitch in $100 \mathrm{~mL}$ solvent. ${ }^{* *}$ Aromaticity index determined from ${ }^{13} \mathrm{C}$ n.m.r. spectra

Table 2: Properties of the boron model compounds

\begin{tabular}{llc}
\hline Boron model compound & Formula & B, wt. \% \\
[CAS No.] & & \\
\hline $\begin{array}{l}\text { Methyl boronic acid (MBA) } \\
{[13061-96-6]}\end{array}$ & $\mathrm{CH}_{3} \mathrm{~B}(\mathrm{OH})_{2}$ & 18.06 \\
$\begin{array}{l}\text { Boric acid (BA) [10043-35-3] } \\
\text { 2-(Benzyloxy)phenylboronic acid (BPA) }\end{array}$ & $\mathrm{H}_{3} \mathrm{BO}_{3}$ & 17.48 \\
$\begin{array}{l}\text { [190661-29-1] } \\
\text { 4-Dibenzofuranboronic acid (DBA) }\end{array}$ & $\mathrm{C}_{6} \mathrm{H}_{5} \mathrm{CH}_{2} \mathrm{OC}_{6} \mathrm{H}_{4} \mathrm{~B}(\mathrm{OH})_{2}$ & 4.74 \\
$\begin{array}{l}\text { 2-Phenoxyphenylboronic acid (PBA) } \\
{[108238-09-1]}\end{array}$ & $\mathrm{C}_{12} \mathrm{H}_{9} \mathrm{BO}_{3}$ & 5.10 \\
p-Tolylboronic acid (TBA) & & \\
{$[5720-05-8]$} & $\mathrm{C}_{6} \mathrm{H}_{5} \mathrm{OC}{ }_{6} \mathrm{H}_{4} \mathrm{~B}(\mathrm{OH})_{2}$ & 5.05 \\
Phenylboronic acid (PLA) & $\mathrm{CH}_{3} \mathrm{C}_{6} \mathrm{H}_{4} \mathrm{~B}(\mathrm{OH})_{2}$ & 7.95 \\
{$[98-80-6]$} & $\mathrm{C}_{6} \mathrm{H}_{5} \mathrm{~B}(\mathrm{OH})_{2}$ & 8.87 \\
\hline
\end{tabular}


Each sample bottle was kept for thirty days and shaken intermittently. Thereafter the

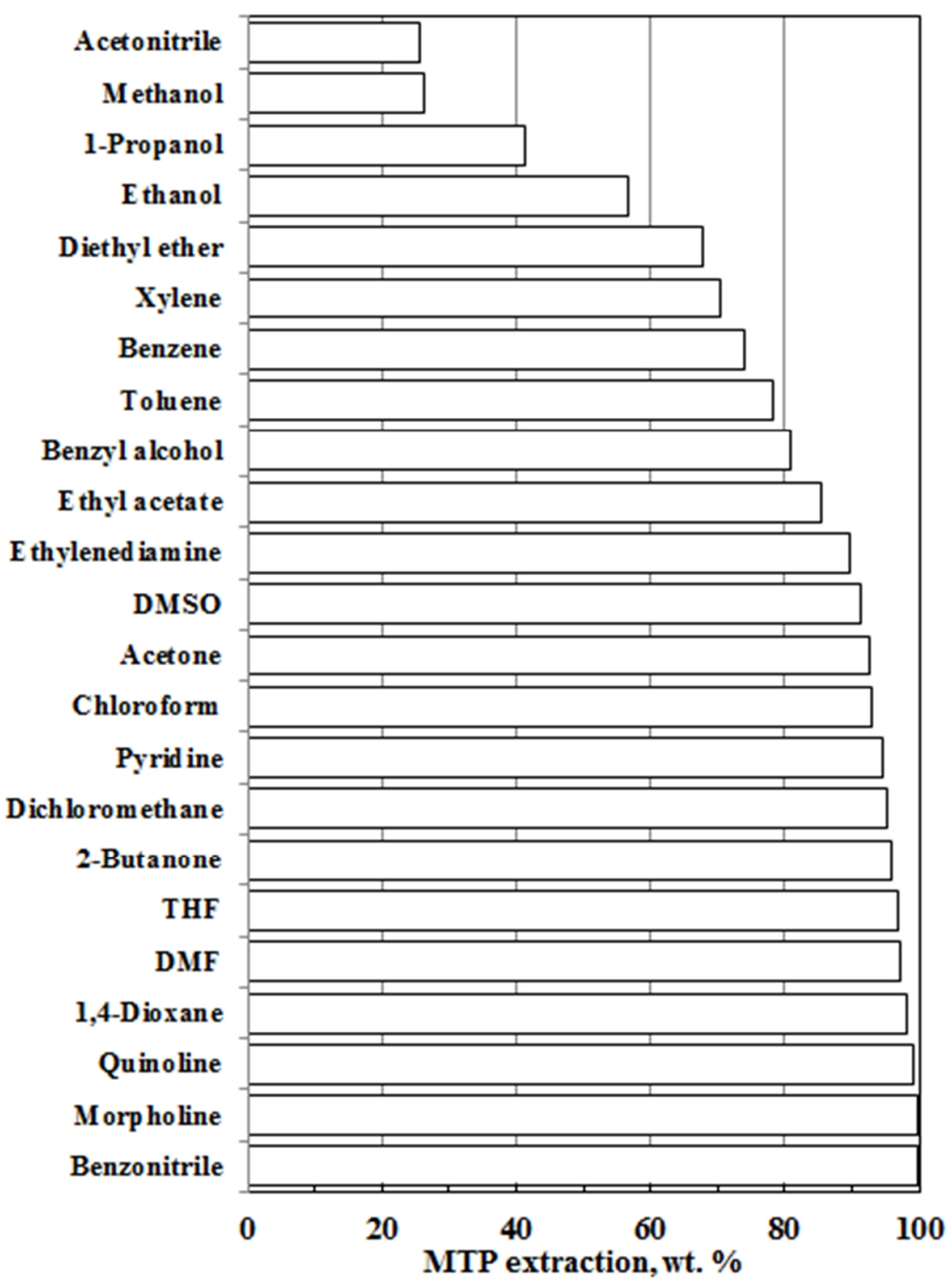

Fig. 1 Solvent extraction results obtained at ambient temperature on contacting $20 \mathrm{~g}$ MTP pitch with $100 \mathrm{~mL}$ solvent for 30 days.

insoluble residues were recovered on $8 \mu \mathrm{m}$ pore size No. 2 Whatmann ${ }^{\circledR}$ filter paper using vacuum filtration. The residues were dried at $80{ }^{\circ} \mathrm{C}$ in a convection oven to constant mass. 


\subsubsection{Reflux extractions}

MTP reflux extractions were performed using methanol, toluene and benzene. This method utilized $2 \mathrm{~g}$ MTP that was transferred into a $250 \mathrm{~mL}$ round bottom flask to which $100 \mathrm{~mL}$ solvent was added. The solution mixture was heated and maintained under reflux for 30 minutes. Residue was again filtered under vacuum using an $8 \mu \mathrm{m}$ pore size No. 2 Whatmann ${ }^{\circledR}$ filter paper. The residue was subsequently washed with hot portions of the corresponding solvent until the filtrate was clear. This was done to ensure that the residue was free of all soluble fractions.

\subsubsection{Simulated boron extractions}

Pitch samples were spiked with 1000 ppm boron as follows. The calculated amount of the model compound was added to the MTP previously placed in a round bottom flask. The mixture was heated gently using a heating mantle. It was swirled when the pitch started to melt to aid dispersion and dissolution of the boron model compound. Initially the model compounds were visible as small white specks dispersed in the dark black and viscous pitch phase. Heating and swirling was continued until the mixture appeared uniform on visual inspection. After forming a uniform mixture, the flask was removed from the heating mantle and cooled to ambient temperature.

Both neat and boron-spiked MTP samples were reflux-extracted with methanol as follows. Boron extractions were conducted using a pitch: methanol mass ratio of 1:1.564. However, this ratio was varied down to $1: 1.32$ for neat pitch extractions. The predetermined quantity of methanol was added to the round bottom flask. The mixture was reflux-extracted for $2 \mathrm{~h}$ and then left to cool to ambient temperature. Two layers formed upon cooling. The top layer was a methanol-rich phase and it was separated from the pitch-rich phase by decanting. The pitch content of both phases was determined by placing them in $100 \mathrm{~mL}$ Petri 
dishes. Most of the solvent was allowed to evaporate before the samples were dried at $80{ }^{\circ} \mathrm{C}$ in a convection oven. The boron contents of the pitch-rich residue phases were determined by inductively coupled plasma optical emission spectroscopy (ICP-OES) based on ASTM D 5158-02.

\subsection{Pitch characterization}

\subsubsection{Elemental analysis}

Determination of carbon, hydrogen, nitrogen and sulphur contents of parent MTP and its insoluble fractions was carried out using a Carlo Erba NA 1500 C/N/S Analyser.

\subsubsection{Softening point}

The softening point of MTP pitch was determined using a TA Q400 V22.1 thermomechanical analyser (TMA) fitted with a penetration probe. A force of $0.05 \mathrm{~N}$ was applied, the nitrogen flow rate was $50 \mathrm{~mL} \cdot \mathrm{min}^{-1}$ and the temperature was scanned at $2{ }^{\circ} \mathrm{C} \cdot \mathrm{min}^{-1}$.

\subsubsection{Fourier transform infrared spectroscopy (FTIR)}

FTIR spectra were collected with A Perkin Elmer Spectrum RX IFT-IR system equipped with MIRacle ${ }^{\mathrm{TM}}$ attenuated total reflectance (ATR) cell from Pike Technologies. The instrument's resolution was $2 \mathrm{~cm}^{-1}$. The spectra were recorded in the range 4000-600 $\mathrm{cm}^{-1}$ and represent the averaging of 32 scans collected at intervals of $1 \mathrm{~cm}^{-1}$.

\subsubsection{Solid-state ${ }^{13} \mathrm{C}$ n.m.r.}

Solid-state nuclear magnetic resonance (n.m.r.) spectra were collected on a Varian VNMRS $500 \mathrm{MHz}$ two-channel spectrometer fitted with a Chemagnetics ${ }^{\mathrm{TM}} \mathrm{T} 3 \mathrm{HX}$ MAS probe comprising four $4 \mathrm{~mm}$ zirconia rotors. Cross-polarization (CP) spectra were recorded at 
ambient temperature with proton decoupling, a $2.9 \mu \mathrm{s} 90^{\circ}$ pulse, and a recycle delay time of 2 s. The power parameters were optimized for the Hartmann-Hahn match; the radio frequency fields were $\gamma_{C} B_{1 \mathrm{C}}=\gamma_{\mathrm{H}} \mathrm{B}_{1 \mathrm{H}} \approx 56 \mathrm{kHz}$. The contact time for cross-polarization was $1.0 \mathrm{~ms}$ after optimization with a variable contact time experiment. One-pulse spectra were recorded at ambient temperature with proton decoupling, a $2.9 \mu \mathrm{s} 90^{\circ}$ pulse, and a recycle delay time of $80 \mathrm{~s}$. The free induction decay had 1787 complex points Fourier transformed with $20 \mathrm{~Hz}$ line broadening. Magic-angle-spinning (MAS) was performed at $9 \mathrm{kHz}$. Adamantane was used as an external chemical shift standard where the downfield peak was referenced to $38.3 \mathrm{ppm}$.

\subsubsection{MALDI-TOF}

An Applied Biosystems Voyager-DE STR matrix-assisted laser desorption/ionization time of flight (MALDI-TOF) spectrometer was used in the reflector mode. The target plate was positively charged and set to $20 \mathrm{kV}$. The mass range was scanned from 20 to $1000 \mathrm{~m} / \mathrm{z}$. Each sample was dissolved in $1 \mathrm{~mL}$ chloroform and spotted onto the plate without the matrix. After spotting, the samples were allowed to dry before being analysed. $\alpha$-Cyano-4hydroxycinnamic acid was used as the matrix. The operating parameters included a delayed extraction mode, an extraction delay time of $500 \mathrm{~ns}$, a manual acquisition control, and a grid voltage of $70 \%$.

\subsubsection{Thermogravimetric analysis (TGA)}

The pyrolysis behaviour of MTP and its soluble and insoluble fractions was determined using a Mettler Toledo TGA/SDTA A851 thermal analyser. Approximately $20 \mathrm{mg}$ of each sample was heated in a $70 \mu$ l alumina pan from 25 to $1000{ }^{\circ} \mathrm{C}$ at a heating rate of $10{ }^{\circ} \mathrm{C} \mathrm{min}-1$ in nitrogen flowing at $50 \mathrm{~mL} \mathrm{~min}^{-1}$.

\section{Results and Discussion}




\subsection{Solvent extractions}

Fig. 1 reports the fraction of pitch extracted by contacting $20 \mathrm{~g}$ pitch with $100 \mathrm{~mL}$ of solvent for 30 days at ambient temperature. Quinoline, morpholine, 1,4-dioxane, dimethylformamide (DMF), tetrahydrofuran (THF) and 2-butanone and benzonitrile were the most effective extraction solvents. All of them solubilized more than $95 \%$ of the pitch. Cyclohexane, $n$ hexane and formamide (not shown in Fig. 1) extracted less than $1 \%$ of the pitch. Blanco and Guillén [16] previously observed the very low solubility of coal tar pitch in formamide.

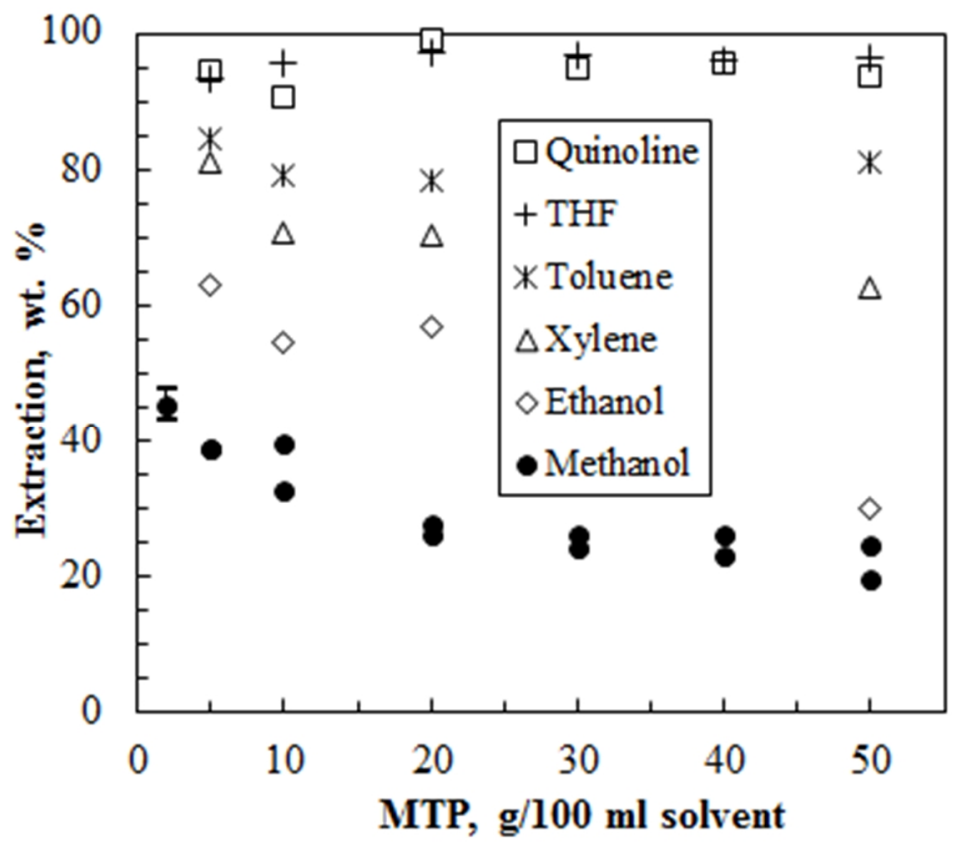

Fig. 2 Effect of the pitch to solvent ratio on the MTP extraction yield for selected organic solvents.

Fig. 2 shows the effect of the pitch to solvent ratio on the degree of MTP extraction for the solvents tested at room temperature. No significant variation was found for DMF, quinoline, THF, toluene and pyridine. This suggests that the solubility limit of MTP in these solvents was not reached and it should therefore exceed $50 \mathrm{~g} / 100 \mathrm{~mL}$ solvent. The degree of MTP extraction decreased with pitch to solvent ratio for xylene, ethanol, and methanol. This 
indicates that the solubility limit of the pitch in these solvents had been reached. The degree of extraction with methanol as solvent decreased from about 45 wt. $\%$ at $2 \mathrm{~g} \mathrm{MTP} / 100 \mathrm{~mL}$ solvent to less than 25 wt. $\%$ at $50 \mathrm{~g} \mathrm{MTP} / 100 \mathrm{~mL}$ methanol.

Methanol was chosen for boron extraction experiments on the basis that the pitch showed a lower solubility in this solvent. Furthermore, it is likely that organic boron in the pitch could be present as compounds with a boronic acid functionality. Boronic acids and boric acid have a distinct affinity to alcohols and may even react with them to form the corresponding esters [17]. Such esters are usually significantly less polar and they are consequently more volatile. This could facilitate their removal when the methanol solvent is stripped from the pitch. Hydroxyl compounds have been used to remove boron from fresh waters [18]. Ideally, the extractive solvent must not dissolve the pitch at all, except those compounds containing boron.

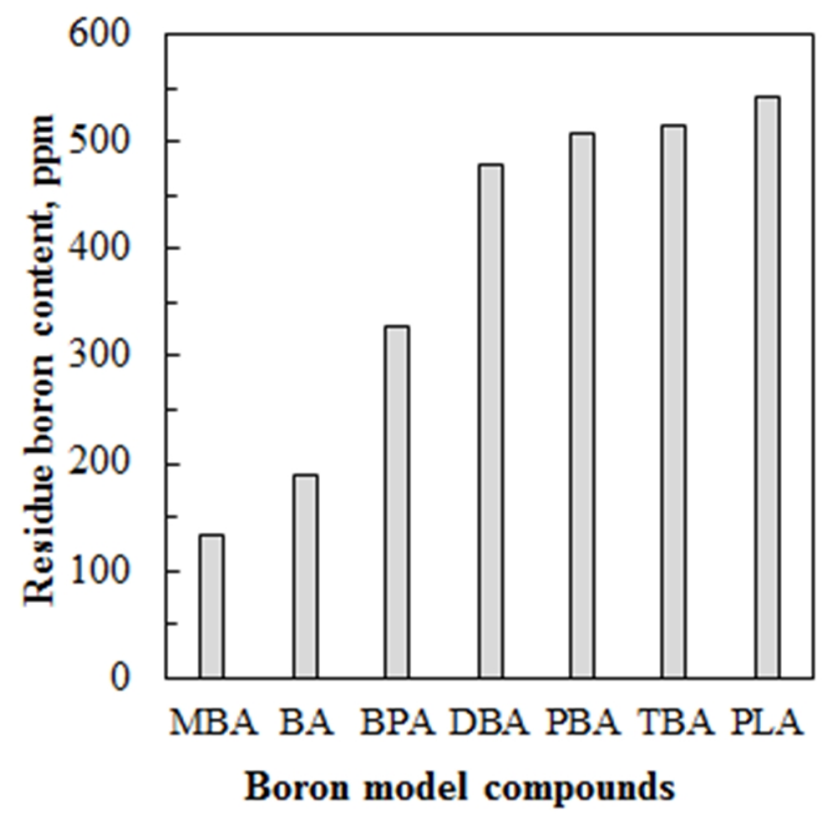

Fig. 3 Apparent partition coefficients and boron content of MTP residues after $2 \mathrm{~h}$ reflux extraction with methanol. The pitch samples were initially spiked with $1000 \mathrm{ppm}$ boron by adding the model compounds listed in Table 2. 
Fig. 3 shows the boron content of MTP residues recovered after $2 \mathrm{~h}$ reflux-extraction with methanol. The pitch samples were spiked with $1000 \mathrm{pm}$ boron. The pitch to methanol ratio was set at $50.5 \mathrm{~g}$ pitch/100 $\mathrm{mL}$ methanol, i.e. a mass ration of 1:1.56. Fig. 3 shows that methanol extraction effectively reduced the boron content to values ranging from $133 \mathrm{ppm}$ (methyl boronic acid) and $542 \mathrm{ppm}$ (phenyl boronic acid). The former compound and also boric acid were removed most effectively and this is attributed to the formation of highly volatile methyl esters. It is likely that some of the other boron compounds were also stripped from the pitch residues as volatile boronic acid esters when the methanol was distilled off.

\subsection{Characterization of pitch fractions from reflux extractions}

The properties of the MTP and the residues, obtained following reflux solvent extractions with $2 \mathrm{~g} \mathrm{pitch} / 100 \mathrm{~mL}$ solvent, are presented in Table 1 . After extraction the pitch content of the pitch-rich and methanol-rich phases were $76 \pm 2$ wt. $\%$ and $27 \pm 1$ wt. $\%$ respectively. The pitch residue remaining after extraction was $54.7 \pm 2.3 \mathrm{wt}$. \%. Thus more than half the pitch was methanol insoluble but almost all of it was extracted by toluene and benzene. The softening point of the parent pitch was $38.5{ }^{\circ} \mathrm{C}$ and that of the methanol insoluble fraction was $59.6{ }^{\circ} \mathrm{C}$. As expected, the MTP elemental composition was dominated by the carbon and hydrogen content. As previously observed by Sima et al. [3], the oxygen content of MTP pitch exceeds the nitrogen and sulphur levels. The latter authors attributed the high oxygen concentration of MTP to the presence of significant quantities of phenolic compounds.

The attenuated total reflection Fourier transform infrared (ATR-FTIR) spectrum of the MTP methanol insoluble fraction in Fig. 4 differed only slightly from those of parent MTP. The bands in the region $900-700 \mathrm{~cm}^{-1}$ are due to out-of-plane vibrations of aromatic C-H bonds [19]. All spectra featured characteristic aromatic and aliphatic $\mathrm{C}-\mathrm{H}$ stretching bands located just above $3000 \mathrm{~cm}^{-1}$ and near $2920 \mathrm{~cm}^{-1}$ respectively [19]. The ratio of the 


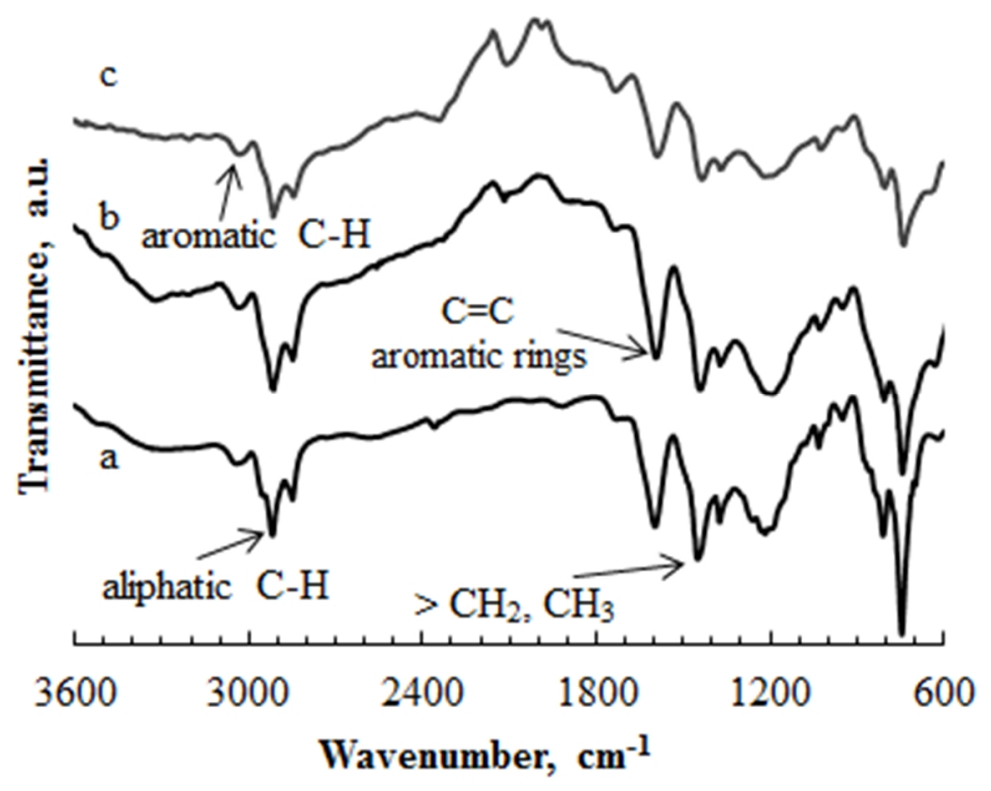

Fig. 4 ATR-FTIR spectra of (a) neat MTP; (b) methanol soluble, and (c) the methanol insoluble fractions.

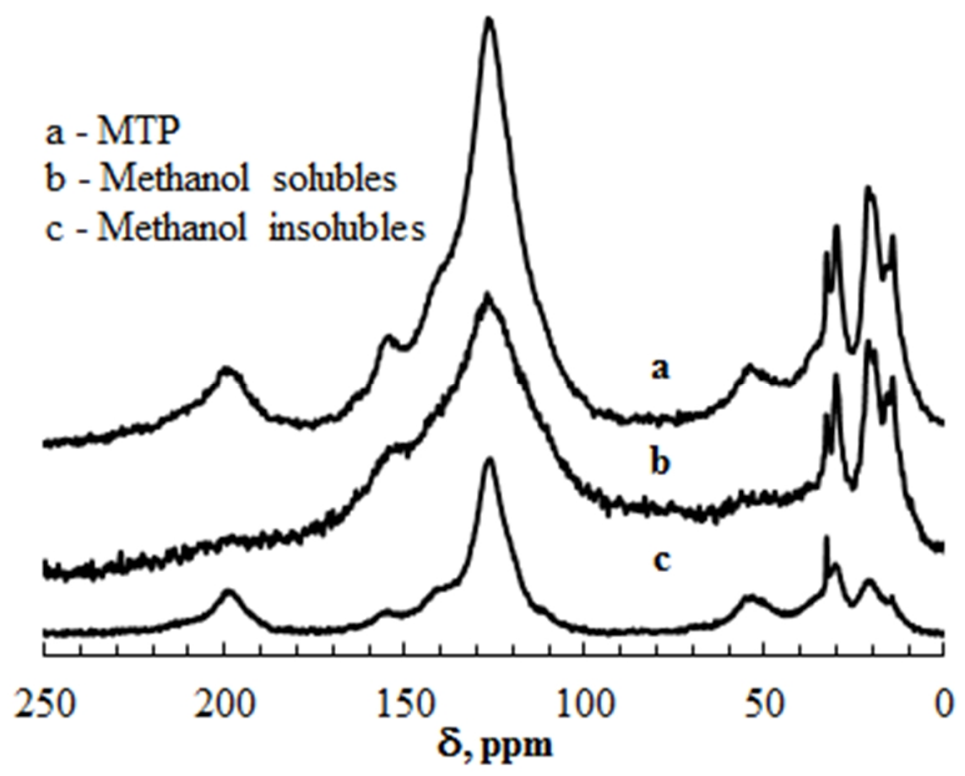

Fig. 5 Solid-state ${ }^{13}$ C n.m.r. CP MAS spectra of MTP and its methanol soluble and insoluble fractions. 


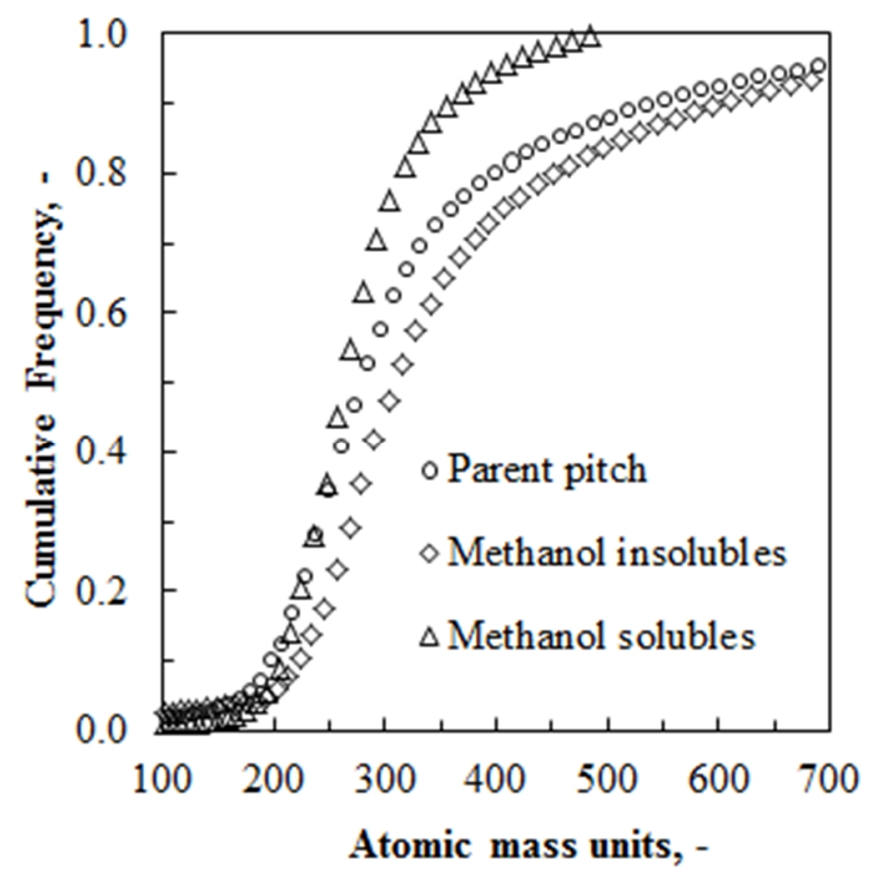

Fig. 6 Cumulative frequency distributions from the MALDI mass spectra of the MTP parent pitch, its methanol insoluble and soluble fractions.

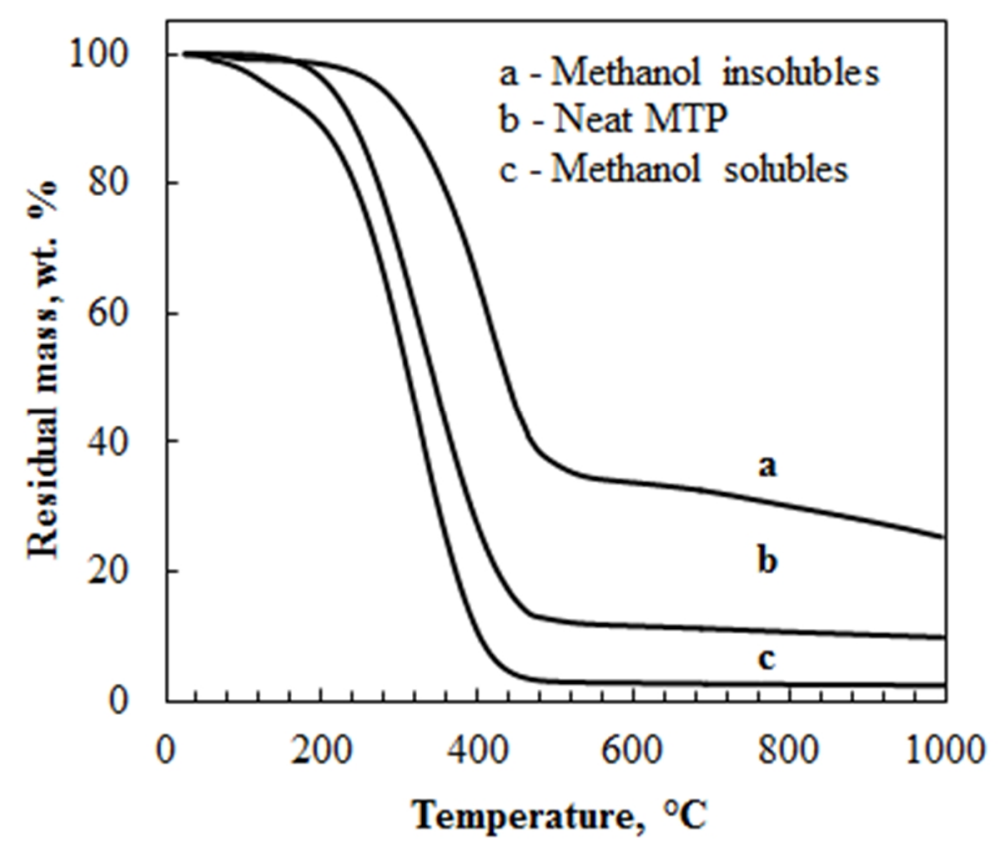

Fig. 7 TG curves of MTP and its methanol soluble and insoluble fractions obtained in a nitrogen atmosphere. Temperature was scanned at $10{ }^{\circ} \mathrm{C} \cdot \mathrm{min}^{-1}$ to $1000{ }^{\circ} \mathrm{C}$. 
absorbance maxima corresponding to these bands also provides an indication of the aromaticity of the pitches [20]. The FTIR spectra for the neat pitch and its methanol fractions all yielded the same value of $\mathrm{A}_{3050} / \mathrm{A}_{2920} \approx 0.20$. This implies that the aromaticity of the methanol soluble and insoluble fractions were rather similar.

Fig. 5 shows the solid-state ${ }^{13}$ C n.m.r. CP MAS spectra of MTP and its solvent fractions. The asymmetric peak in the region of $127 \mathrm{ppm}$ shift indicates the presence of aromatic carbons [21]. The peaks in the region $0-50 \mathrm{ppm}$ are due to the presence of aliphatic carbons. The peaks located at $200 \mathrm{ppm}$ and $55 \mathrm{ppm}$ represent spinning sidebands for the aromatic carbons and the aliphatic carbons respectively. The aromaticity index $\left(f_{\mathrm{a}}\right)$ values reported in Table 1 were estimated from the ${ }^{13} \mathrm{C}$ n.m.r. spectra using the technique proposed by Mokoena et al. [22] that corrects for the influence of these spinning sidebands. This index provides a semi-quantitative measure of the aromaticity of pitches [22, 23] suitable for comparing trends. Compared to the parent pitch, the benzene and toluene insoluble fractions featured higher $f_{\mathrm{a}}$ values and lower sulphur contents. The higher $\mathrm{C} / \mathrm{H}$ ratios found for these residues are consistent with higher aromaticity indices. However, the benzene and toluene extractions yielded lower residue values as the pitch was almost completely soluble in these solvents. In contrast, the methanol extraction residue featured a slightly lower aromaticity index and somewhat higher sulphur content than the parent pitch. The $\mathrm{C} / \mathrm{H}$ ratio of the methanol insoluble fraction was only slightly higher than that of the parent pitch.

Fig. 6 shows cumulative frequency distributions estimated from MALDI mass spectra. It reveals that, compared to other commercial coal tar pitches, the isotropic MTP comprises lower molecular mass compounds. Fig. 6 clearly shows that the methanol preferentially solubilized the lower molar mass compounds. Consequently the extraction residue featured a higher molar mass distribution. The weight average molecular mass $\left(\mathrm{M}_{\mathrm{w}}\right)$ of the parent pitch, the methanol soluble fraction and the methanol insoluble fraction were 403, 288 and 437 
a.m.u. respectively. The polydispersity index (PDI) is defined by the ratio of the weight average to the number average molar masses (PDI $\left.=M_{w} / M_{n}\right)$. It provides a measure of the width of the molar mass distribution. The PDI of the parent pitch and the methanol insoluble fraction were similar equalling $\mathrm{PDI}=1.23$ and $\mathrm{PDI}=1.22$ respectively. The methanol soluble pitch fraction featured a narrower molar mass distribution with PDI $=1.06$.

Thermogravimetric analysis (TG) traces are reported in Fig. 7 for MTP and the methanol derived fractions. The carbon yield was taken as the mass residue remaining at $1000{ }^{\circ} \mathrm{C}$ and it is reported in Table 1 . MTP had a low carbon yield of only 9 wt. $\%$ at $1000{ }^{\circ} \mathrm{C}$. The low carbon yield of MTP is attributed to a high content of low molecular mass species with significant volatility [3]. Fig. 7 shows that, compared to neat MTP, mass loss for the methanol soluble and methanol insoluble fractions commenced at lower and higher temperatures respectively. The corresponding carbon yields were 2.4 wt. $\%$ and 25 wt. \%. The toluene insoluble fractions had the highest carbon yield (53 wt. \%) closely followed by benzene insoluble fraction with the carbon yield of $51 \mathrm{wt.} \%$.

\section{Discussion and conclusions}

Medium-temperature pitch from the Sasol-Lurgi gasifier is a potential source for nuclear grade graphite. However, its intrinsic boron content might on occasion be too high for this application. Unfortunately the boron content of the pitch sample received for the present study was below the detection limit of the available instrumental techniques. It was therefore of interest to determine whether simple solvent extraction was able to reduce the boron content of pitch samples spiked with organic boron model compounds at $1000 \mathrm{ppm} \mathrm{B}$. The preferred extractive solvent would have a high affinity for the boron compounds but 
otherwise dissolve little or none of the pitch. Most organic solvents proved unsuitable from this perspective as the pitch was highly soluble in them. MTP was almost completely soluble in dimethylformamide, quinoline, 2-butanone, tetrahydrofuran and pyridine. The solubility limit in these solvents thus exceeded $50 \mathrm{~g} \mathrm{MTP} / 100 \mathrm{~mL}$ solvent. MTP was virtually insoluble in $n$-hexane, cyclohexane and formamide and but sparingly soluble in acetonitrile, methanol and ethanol.

Methanol was selected as extractive solvent instead of acetonitrile as it is more volatile and its alcohol functionality is more suited to interact and even react with the boronic acid model compounds tested. Single stage extraction tests conducted at a pitch to methanol ratio of $2 \mathrm{~g} \mathrm{MTP} / 100 \mathrm{~mL}$ methanol and at reflux temperatures yielded two liquid phases on cooling. The pitch concentration in the methanol-rich phase was $27 \mathrm{wt} . \%$ and in the pitchrich phase it was 76 wt. $\%$. The latter contained 54.7 wt. $\%$ of the original pitch mass. The $\mathrm{C} / \mathrm{H}$ ratio determined from elemental analysis, FTIR spectroscopy and the aromaticity index estimated from ${ }^{13} \mathrm{C}$ CP MAS n.m.r. indicated negligible difference in the aromaticity indices of the methanol soluble and methanol insoluble pitch fractions. However, the softening point of the latter was about $20^{\circ} \mathrm{C}$ higher than the value for the neat pitch. MALDI-TOFF spectra revealed that the methanol preferentially solubilized compounds with a lower molar mass. This suggests that the higher carbon yield found for the methanol insolubles was due to a lower volatility of the higher molar mass compounds retained in this pitch fraction.

Pitch samples were spiked with 1000 ppm boron using a variety of boronic acid compounds. Following extraction at reflux temperature using a pitch to solvent ratio of 50,5 $\mathrm{g}$ MTP/100 mL methanol, the pitch-rich phase liquid phase was separated and the residue recovered by evaporating the methanol. These single stage extractions successfully reduced the boron content of the spiked pitch residues by a factor ranging from about 1.8 (phenyl 
boronic acid) to about 7.5 (methyl boronic acid). The latter and boric acid was most easily removed. This is attributed to the formation of highly volatile methyl esters.

\section{Acknowledgements}

This work is based upon research supported by the SANHARP and the South African Research Chairs Initiative of the Department of Science and Technology and the National Research Foundation. Any opinion, findings and conclusions or recommendations expressed in this work are those of the authors and therefore the SANHARP, NRF and DST do not accept any liability with regard thereto.

\section{References}

[1] Edwards IAS. Structure in carbon and carbon forms. In: Marsh H, editor. Introduction to carbon science, Butterworth: Butterworth \& Co; 1989, p. 1-36.

[2] Burchell TD. Carbon materials for nuclear energy applications In: Marsh $\mathrm{H}$, Rodríguez-Reinoso F, editors. Sciences of carbon materials, Univesidad de Alicante: Secretariado de Publicaciones; 2000, p. 117-47.

[3] Sima L, Blanco C, Santamaria R, Granda M, Slaghuis H, Menendez R. Relationship between chemical composition and pyrolysis behaviour of a medium temperature pitch. Fuel Process Technol 2003;84:63-77.

[4] Zander, M. Chemistry and properties of coal-tar and petroleum pitch, In: Marsh H, Rodríguez-Reinoso F, editors. Sciences of carbon materials, Univesidad de Alicante: Secretariado de Publicaciones; 2000, p. 205-257.

[5] Guillén MD, Blanco J, Canga JS, Blanco CG. Study of effectiveness of 27 organic solvents in the extraction of coal tar pitch. Energy Fuels 1991;5:188-92.

[6] Guillén MD, Iglesias MJ, Dominguez A, Blanco CG. Semiquantitative FTIR analysis of coal tar pitch and its extracts and residues in several organic solvents. Energy Fuels 1992;6:518-25.

[7] Guillén MD, Dominguez A, Iglesias MJ. Fourier transform infrared study of coal tar pitches. Fuel 1995;74:1595-98.

[8] Katritzky AR, Fara DC, Yang H, Tämm k. Quantitative measures of solvent polarity. Chem Rev 2004;104:175-98. 
[9] Zhou JS, Wei XY, Dou YQ, Gong GZ, Peng Li, Yue XM, Bo Chen, Wang FW, Feng $\mathrm{CH}$, Zong ZM. Solvent cutting to make superior coal tar pitches. Adv Mater Res 2011;239-242:1296-1299.

[10] Kelly BT. Introduction to graphite. In: Kelly BT, editor. Physics of graphite, London and New Jersey: Applied Science Publishers; 1981, p. 1-33.

[11] Hawthorne MF. Biochemical applications of boron cluster. Pure Appl Chem $1991 ; 63: 327-34$.

[12] Baker DE. Graphite as a neutron moderator and reflector material. Nucl Eng Des 1970;14:413-44.

[13] Mochizuki Y, Sugawara K, Enda Y. Effect of pretreatment and additives on boron release during pyrolysis and gasification of coal. Energy Fuels 2009;23:4502-06.

[14] Goodarzi F, Swaine DJ. Behavior of boron in coal during natural and industrial combustion processes. Energy Sources Part A 1993;15:609-22.

[15] Boyd RJ. The partitioning behaviour of boron from tourmaline during ashing of coal. Int J Coal Geol 2002;53:43-54.

[16] Blanco CG, Guillén MD. Study of relationships between solvent effectiveness in coal tar pitch extractions and solvent solubility parameters. Ind Eng Chem Res 1991;30:1579-82.

[17] Hall DG. Structure, Properties, and Preparation of Boronic Acid Derivatives. Overview of Their Reactions and Applications. In: Hall DG editor. Boronic Acids: Preparation and Applications in Organic Synthesis and Medicine, Weinheim; WileyVCH; 2006, pp. 1-99.

[18] Ayers P, Dudeney AWL, Kahraman F. Solvent extraction of boron with 2-ethyl-1,3hexanediol and 2-chloro-4-(1,1,3,3-tetramethylbutyl)-6-methylol-phenol. J Inorg Nucl Chem 1981;43:2097-2100.

[19] Coates J. Interpretation of infrared spectra, a practical approach. In: Meyers RA editor. Encyclopedia of analytical chemistry, Chichester: John Wiley \& Sons; 2000, p. 10815-37.

[20] Cunyan W. Determination of aromaticity indices of coal liquids by infrared spectroscopy. Fuel 1987;66:840-43.

[21] Pasto DJ, Johnson CR. Laboratory text for organic chemistry, A source for chemical and physical techniques. 1st ed. Englewood Cliffs, New Jersey: Prentice-Hall Inc; 1989. 
[22] Mokoena K, Van der Walt TJ, Morgan TJ, Herod AA, Kandiyoti R. Heat treatment of medium-temperature Sasol-Lurgi gasifier coal-tar pitch for polymerizing to higher value products. Fuel 2008;87:751-60.

[23] Suggate RP, Dickinson WW. Carbon NMR of coals: the effect of coal type and rank. Int J Coal Geol 2004;57:1-22. 